\title{
MODELAGEM DA PRODUTIVIDADE DO MILHO SAFRINHA EM FUNÇÃO DAS CONDIÇÕES CLIMÁTICAS DO MATO GROSSO DO SUL
}

\author{
APARECIDO, Lucas Eduardo de Oliveira - lucas.aparecido@ifms.edu.br \\ Instituto Federal de Mato Grosso do Sul - Naviraí/ IFMS \\ TORSONI, Guilherme Botega - guilherme.torsoni@ifms.edu.br \\ Instituto Federal de Mato Grosso do Sul - Naviraí/ IFMS \\ MESQUITA, Daniel Zimmerman - daniel.mesquita@ifms.edu.br \\ Instituto Federal de Mato Grosso do Sul - Naviraí/ IFMS \\ MENESES, Kamila Cunha de - kamila.meneses31@outlook.com \\ Universidade Estadual Paulista Júlio de Mesquita Filho - Jaboticabal / UNESP \\ MORAES, José Reinaldo da Silva Cabral de - jose.moraes@ifms.edu.br \\ Instituto Federal de Mato Grosso do Sul - Naviraí/ IFMS
}

\begin{abstract}
RESUMO: A previsão sazonal da produtividade dos cultivos pode colaborar para a mitigação de efeitos adversos da variabilidade climática. Portanto, objetivou-se calibrar um modelo geral de previsão de produtividade de milho safrinha para o estado do Mato Grosso do sul usando elementos climáticos. Foi utilizado séries históricas de dados climáticos como radiação solar global, temperaturas média, máxima e mínima do ar, umidade relativa, velocidade do vento e precipitação pluvial durante o período de 19832018, e dados fitotécnicos de áreas produtivas de milho em Mato Grosso do Sul para estimar modelos e gerar mapas de produtividade no estado. A produtividade média das localidades da região norte foi maior em relação as localidades do sul do estado. $O$ modelo desenvolvido para estimar a produtividade do milho safrinha em função das variáveis climáticas foi significativo $(p<0,05)$, com alta precisão e acurácia . O modelo calibrado apresentou relação significativa entre a produtividade do milho safrinha e a temperatura do ar no período de abril a maio. Portanto essa variável meteorológica pode ser utilizada como indicador de riscos climáticos em sistemas de produção de milho no estado do Mato Grosso do Sul.
\end{abstract}

PALAVRAS-CHAVE: Zea mays, microclimatologia, modelo de cultivo, regressão linear múltipla.

\section{MODELING OF SAFRINHA CORN YIELD IN FUNCTION OF THE CLIMATE CONDITIONS OF MATO GROSSO DO SUL}

ABSTRACT: The seasonal forecast of crop yields can contribute to themitigation of adverse effects of climate variability. Therefore, we seek to calibratea general model for forecasting safrinha corn productivity for the state of Mato Grosso do sul using climatic elements. We use historical data series such as global solar radiation, average, maximum and minimum air temperatures, relative humidity, wind speed and rainfall during the period 1983-2018, and phytotechnical data from maize production areas in Mato Grosso do Sul forestimate models and generate productivity maps in the state. The average productivity of locations in the northern region were greater in relation to locations in the south of the state. O model developed to estimate the productivity of off-season corn according to the climatic variables was significant $(p<0.05)$, with high precision and accuracy. The model calibration showed a significant relationship between the productivity of the off-season corn and the air temperature from April to May. So this meteorological variable can be used as an indicator of climatic risks in maize production systems in the state of Mato Grosso do Sul.

KEYWORDS: Zea mays, microclimatology, crop-modelling, regression multiple linear. 


\section{INTRODUÇÃO}

A adaptação dos cultivos à variabilidade climática é um dos principais desafios científicos do século XXI, principalmente em relação ao aumento de temperatura e quantidade de precipitação pluvial (HATFIELD et al., 2011; WALTHALL et al., 2012). A variabilidade climática é responsável por um terço da instabilidade global da produção agrícola (RAY et al., 2015).

A previsão sazonal da produtividade dos cultivos pode colaborar para a mitigação de efeitos adversos (CEGLAR et al., 2018). As informações sobre previsões climáticas podem contribuir em até $12 \%$ na elevação dos lucros médios da produção agrícola, equivalente ao de melhoramento de plantas (RODRIGUEZ et al., 2018). Isso demonstra o quanto é importante o desenvolvimento de técnicas acuradas de previsão de safras (APARECIDO et al., 2018).

O milho tem uma grande importância mundial no consumo humano e animal, e como matéria-prima para a indústria de alta tecnologia, como no caso da produção de etanol (OLIVEIRA et al., 2018). Os maiores produtores mundiais de milho são os Estados Unidos ( 345 milhões de toneladas), a China ( 224 milhões de toneladas) e o Brasil ( $~ 81$ milhões de toneladas). A região CentroOeste do Brasil é a maior produtora de milho ( 42 milhões de toneladas). 0 estado do Mato Grosso do Sul (MS) é um dos maiores produtores de milho da região, com uma produção e produtividade média de 7,3 milhões de toneladas e 4,8 $\mathrm{mil} \mathrm{kg} \mathrm{ha}^{-1}$, respectivamente (CONAB, 2018).

As quedas na produtividade do milho ocorrem por influência das condições climáticas, potencial genético de híbridos da cultura, manejo nutricional e do manejo ineficiente de pragas e doenças (GARCIA et al., 2018). Dentre esses fatores, a influência do clima na produtividade deste cultivo é a que se tem o menor poder de controle (SCHAUBERGER et al., 2017).

A quantidade e a distribuição de chuva são, geralmente, os fatores que mais influenciam na variabilidade da produtividade sob condições de sequeiro (BERGAMASCHI et al., 2004; ARAUS et al., 2012), visto que o milho demanda grande disponibilidade de água para seu desenvolvimento (GONG et al., 2015). A seca pode reduzir a germinação das plantas durante o estabelecimento da cultura em campo.

O estresse hídrico reduz à expansão da área foliar, consequentemente, a diminuição da interceptação de radiação solar na folha. Além disso, o déficit hídrico resulta na infertilidade induzida, aborto ou grãos murchos, reduzindo o índice de colheita e no fornecimento de assimilados na fonte, levando a perdas no peso dos grãos (ARAUS et al., 2012).

A previsão da produtividade dos cultivos usando apenas variáveis climáticas é amplamente utilizada em muitos estudos e na construção de modelos, pois não há custo significativo e é de fácil aplicação (BASSO et al., 2013; PENG et al., 2017). Monteiro et al. (2017) estimaram a produtividade de milho no sul do Brasil com base no nível tecnológico dos sistemas de produção e modelos agrometeorológicos relativamente simples, observaram alta correlação entre as produtividades estimada e observada com coeficiente de determinação $\left(R^{2}\right)$ entre 0,76 e 0,92 $(p<0,01)$ e o erro médio absoluto (MAE) inferior a $70 \mathrm{~kg}$ ha-1. 
Alguns trabalhos de previsões de safras com a utilização de dados climáticos são encontrados na literatura, como exemplo, Peng et al. (2017) previram a produtividade de azevém italiano na Coreia do Sul baseada em dados climáticos, e os resultados apoiaram a possibilidade de semear azevém na primavera seguinte, se caso, a semeadura de outono tiver sido perdida, com uma acurácia de $74 \%$.

Ogotu et al. (2018) concluíram que há potencial para prever a produção do milho usando modelos de cultivos e previsões climáticas, e que a previsão variou de acordo com as regiões da África Oriental. Já, Jayakumar e Rajavel (2017) desenvolveram modelos para a previsão de café Arábica e Robusta em Kerala, os quais tiveram um bom coeficiente de determinação, com isso, possibilitaram prever a produtividade do café mais próxima em relação aos anos observados.

Diante desse contexto, este estudo se torna importante para auxiliar nas tomadas de decisões nas áreas produtoras de milho safrinha no estado do Mato Grosso do Sul (MS) e contribuir no planejamento agrícola, para que haja um aumento da produtividade, de forma sustentável. Portanto, objetivou-se calibrar um modelo geral de previsão de produtividade de milho safrinha para o estado do Mato Grosso do sul usando elementos climáticos.

\section{MATERIAL E MÉTODOS}

\section{ÁREA DE ESTUDO E DADOS}

Este estudo utilizou séries históricas de dados climáticos e fitotécnicos de áreas produtivas de milho no Estado de Mato Grosso do Sul (MS), Brasil. As localidades representativas na produção de milho no Mato Grosso do Sul estão apresentadas na Figura 1 e Tabela 1. 


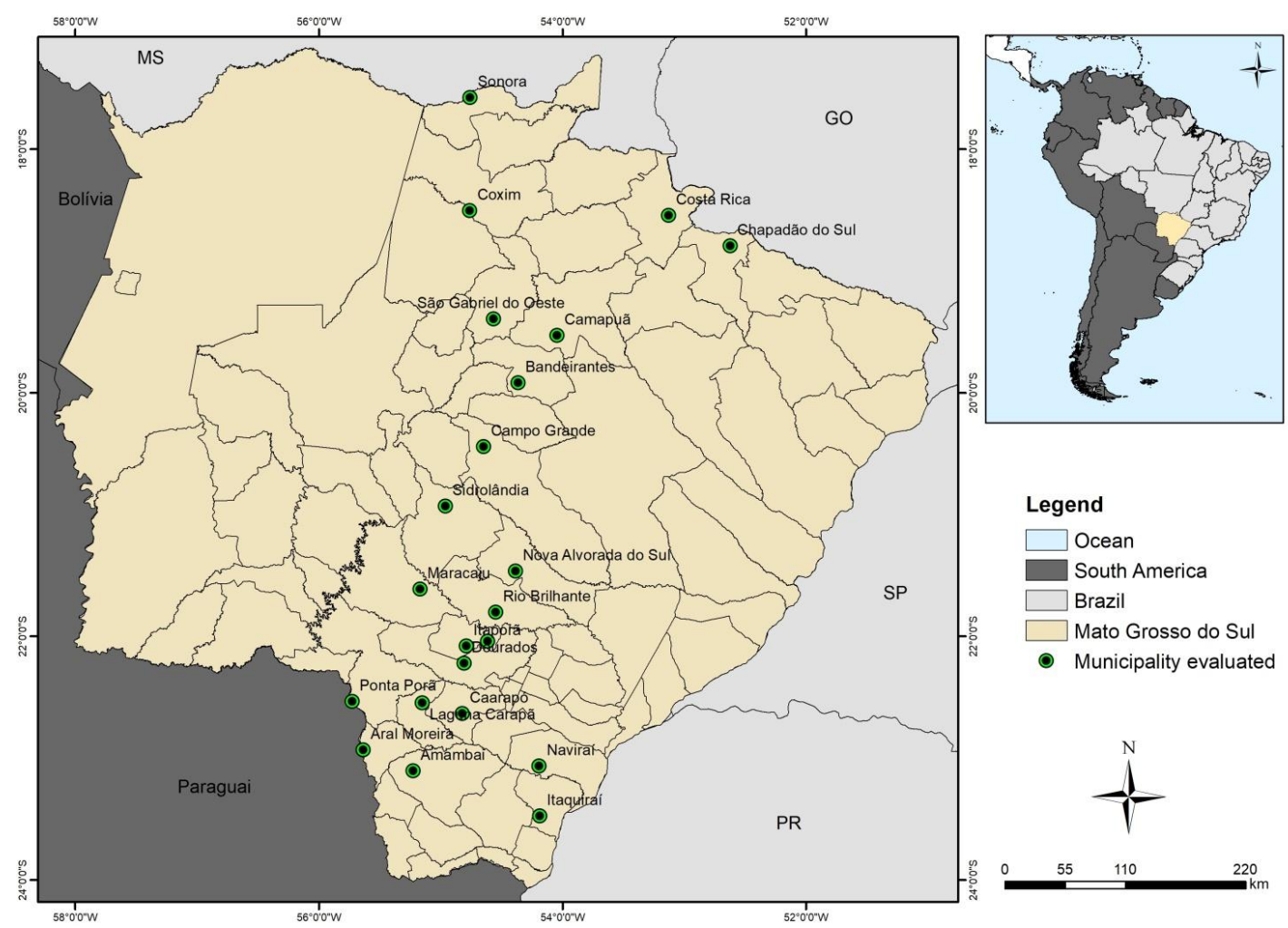

Figura 1 - Localização geográfica das localidades produtoras de milho safrinha no Mato Grosso do Sul, Brasil. Fonte: Autor

Tabela 1 - Descrição geográfica das localidades produtoras de milho safrinha do estado de Mato Grosso do Sul, Brasil.

\begin{tabular}{|c|c|c|c|}
\hline Município & Latitude & Longitude & $\begin{array}{l}\text { Altitude } \\
(\mathrm{m})\end{array}$ \\
\hline Amambai & $23^{\circ} 06^{\prime} 15^{\prime \prime}$ & $55^{\circ} 13^{\prime} 33^{\prime \prime}$ & 480 \\
\hline Aral Moreira & $22056^{\prime} 02^{\prime \prime}$ & $55^{\circ} 38^{\prime} 07^{\prime \prime}$ & 609 \\
\hline Bandeirantes & " 190 '55 04 & $54021^{\prime} 50 "$ & 629 \\
\hline Caarapó & $22038^{\prime} 03^{\prime \prime}$ & "540 49' 20 ' & 471 \\
\hline Camapuã & $19031^{\prime} 53 "$ & $54^{\circ} 02^{\prime} 38 "$ & 409 \\
\hline Campo Grande & $20026^{\prime} 34$ " & 54038 '47" & 532 \\
\hline Chapadão do Sul & $18^{\circ} 47^{\prime} 39 "$ & $52037^{\prime} 22$ & 790 \\
\hline Costa Rica & $18^{\circ} 32^{\prime} 38^{\prime \prime}$ & $53007^{\prime}$ '45 & 641 \\
\hline Coxim & $18030^{\prime} 24 "$ & $54045^{\prime} 36^{\prime \prime}$ & 238 \\
\hline Douradina & $22002^{\prime} 25^{\prime \prime}$ & $54036^{\prime} 46^{\prime \prime}$ & 553 \\
\hline Dourados & $22013^{\prime} 16^{\prime \prime}$ & 54048 '20" & 430 \\
\hline Itaporã & $22004^{\prime} 44^{\prime \prime}$ & $54047^{\prime} 22 "$ & 390 \\
\hline Itaquiraí & $23028^{\prime} 28^{\prime \prime}$ & $54011^{\prime} 06 "$ & 340 \\
\hline Laguna Carapã & $22032^{\prime} 47^{\prime \prime}$ & $55^{\circ} 08^{\prime} 59 "$ & 509 \\
\hline Maracaju & $21^{\circ} 36^{\prime} 52^{\prime \prime}$ & $55^{\circ} 10^{\prime} 06 "$ & 384 \\
\hline Naviraí & $23^{\circ} 03^{\prime} 54^{\prime \prime}$ & $54011^{\prime} 26 "$ & 362 \\
\hline
\end{tabular}




\begin{tabular}{llll} 
Nova Alvorada do Sul & $21^{\circ} 27^{\prime} 57^{\prime \prime}$ & $54^{\circ} 23^{\prime} 02^{\prime \prime}$ & 407 \\
Ponta Porã & $22^{\circ} 32^{\prime} 10^{\prime \prime}$ & $55^{\circ} 43^{\prime} 32^{\prime \prime}$ & 655 \\
Rio Brilhante & $21^{\circ} 48^{\prime} 07^{\prime \prime}$ & $54^{\circ} 32^{\prime} 47^{\prime \prime}$ & 312 \\
São Gabriel do Oeste & $19^{\circ} 23^{\prime} 43^{\prime \prime}$ & $54^{\circ} 33^{\prime} 59^{\prime \prime}$ & 658 \\
Sidrolândia & $20^{\circ} 55^{\prime} 55^{\prime \prime}$ & $54^{\circ} 57^{\prime} 41^{\prime \prime}$ & 484 \\
Sonora & $17^{\circ} 34^{\prime} 37^{\prime \prime}$ & $54^{\circ} 45^{\prime} 28^{\prime \prime}$ & 442 \\
\hline
\end{tabular}

Fonte: IBGE

Os dados de produção $(\mathrm{kg})$, produtividade ( $\mathrm{kg}$ hectare-1), área plantada (hectare) dessas localidades foram coletados do período de 2009-2018 e obtidos na Associação dos Produtores de Milho do Estado de Mato Grosso do Sul (APROMILHO).

Os dados de radiação solar global $\left(\mathrm{Qg}, \mathrm{MJ} \mathrm{m}^{-2} 2 \mathrm{~d}^{-1}\right)$, temperatura média (Tm), máxima (Tmax) e mínima (Tmin) do ar $\left({ }^{\circ} \mathrm{C}\right)$, umidade relativa (UR, \%), velocidade do vento (U2, $\mathrm{m} \mathrm{s}^{-1}$ ) e precipitação pluvial $(P, \mathrm{~mm})$ do período de 1983-2018 foram obtidos da plataforma National Aeronautics and Space Administration/Prediction of World Wide Energy Resources - (NASA/POWER; http://power.larc.nasa.gov), em escala diária. Esta plataforma de dados foi desenvolvida para fornecer informações meteorológicas e os dados foram compilados de várias fontes e derivados de grids com resolução espacial de $0.25^{\circ}$ (latitude-longitude).

\section{CÁlCULO DA EVAPOTRANSPIRAÇÃO POTENCIAL}

A partir dos dados climáticos obtidos foi calculada a Evapotranspiração Potencial (ETP) pelo método Penman-Monteith (PM) (Equação 1). A Organização das Nações Unidas para Agricultura e Alimentação (FAO) propôs usar a equação PM como método padrão para estimar ETP e avaliar outros métodos (ALLEN et al., 1994):

$E T P=\frac{0,408 \times s \times(R n-G)+\frac{\gamma \times 900 \times U_{2} \times(e s-e a)}{T+273}}{s+\gamma \times\left(1+0,34 \times U_{2}\right.}$

em que ETP - Evapotranspiração potencial, em $\mathrm{mm} \mathrm{dia}^{-1} ; R n$ - Radiação liquida, em MJ m $\mathrm{m}^{-2} \mathrm{dia}^{-1} ; G$ - Densidade do fluxo de calor, em MJ m${ }^{-2} \mathrm{dia}^{-1} ; T$ Temperatura média diária do ar, em ${ }^{\circ} \mathrm{C} ; \gamma$ - Constante psicométrica $(0,063 \mathrm{KPa}$ $\left.{ }^{\circ} \mathrm{C}^{-1}\right) ; s$ - Declividade da curva de saturação de vapor, em $\mathrm{KPa}{ }^{\circ} \mathrm{C}^{-1} ; U_{2}$ Velocidade média diária do vento a 2 metros de altura, em $\mathrm{m} \mathrm{s}^{-1} ; e_{a}$ - Pressão parcial de vapor, em KPa e $e_{s}$ e - Pressão de saturação de vapor, média diária, em Kpa.

Para calcular a ETP foi necessário estimar os valores de Rn, $\mathrm{S}$, es e ea (ALLEN et al., 1998), através das Equações 2-10:

es - pressão de saturação de vapor, média diária, (KPa):

$e s=\frac{\mathrm{es}_{\mathrm{Tmax}}+\mathrm{es}_{\mathrm{Tmin}}}{2}$

em que: es é pressão de saturação de vapor média diária (kPa); esTmax é a pressão de saturação de vapor à temperatura máxima (kPa) e esTmin é a 
pressão de saturação de vapor à temperatura mínima (kPa), e são expressas pelas Equações:

$$
\begin{gathered}
\text { esTmax }=0,6108 \times e^{\left(\frac{17,27 \times T_{\max }}{237,3+T_{\max }}\right)} \\
e s T \min =0,6108 \times e^{\left(\frac{17,27 \times T_{\min }}{237,3+T_{\min }}\right)}
\end{gathered}
$$

a) $\mathrm{e}_{\mathrm{a}}$ - pressão parcial de vapor $(\mathrm{KPa})$ :

$e a=\frac{U R_{m e d} \times e s}{100}$

em que URmed é umidade relativa média (\%) e es é pressão de saturação de vapor média diária $(\mathrm{kPa})$.

b) $\mathrm{s}$ - declividade da curva de saturação de vapor $\left(\mathrm{KPa}{ }^{\circ} \mathrm{C}^{-1}\right)$ :

$s=\frac{4098 \times e s}{(T+273)^{2}}$

c) $\mathrm{Rn}$ - radiação líquida $\left(\mathrm{MJ} \mathrm{m}^{-2} \mathrm{dia}^{-1}\right)$ :

$R n=B O C-B O L$

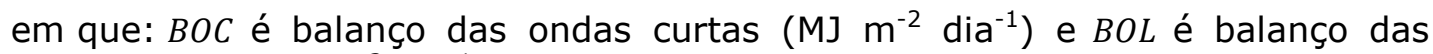

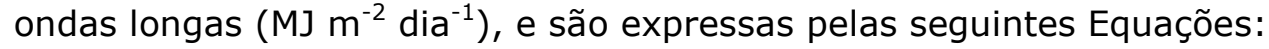

$$
B O C=(1-\alpha) \times R s
$$

em que Rs é a radiação solar incidente $\left(M J \mathrm{~m}^{-2}\right.$ dia ${ }^{-1}$ ) e $\alpha$ é o coeficiente de reflexão da vegetação;

$$
B O L=4,903 \times 10-9[(\text { Tmax. } K 4+\text { Tmin. K4) } / 2][0,34-0,14(\text { ea0 } 0.5)][1,35(\text { Rs } / \text { Rso })-
$$

em que Tmax é a temperatura máxima $\left({ }^{\circ} \mathrm{C}\right)$, Tmin é a temperatura mínima do dia $\left({ }^{\circ} \mathrm{C}\right)$; Rs é a radiação solar incidente $\left(\mathrm{MJm}^{-2} \mathrm{dia}^{-1}\right)$; Rso é a radiação solar incidente na ausência de nuvens $\left(\mathrm{MJm}^{-2} \mathrm{dia}^{-1}\right)$; ea é a pressão atual de vapor (kPa);

$$
R s o=(0,75+2 \times 10-5 \times 11) \times R a
$$

\section{O BALANÇO HÍDRICO CLIMATOLÓGICO}

O balanço hídrico climatológico foi gerado para todas as localidades estudadas segundo a metodologia de Thornthwaite e Mather (1955) (Equações 11-16). Foi utilizada uma capacidade de água disponível igual $40 \mathrm{~mm}$, valor que representa a profundidade efetiva do sistema radicular da cultura do milho.

$$
\begin{aligned}
& \text { Se }(P-P E T)_{i}<0=\left\{\begin{array}{c}
N A C_{i}=N A C_{i-1}+(P-P E T)_{i} \\
A R M_{i}=C A D \times e^{\frac{\left(\mathrm{NAC}_{i}\right)}{C A D}}
\end{array}\right. \\
& \text { Se }(P-P E T)_{i} \geq 0=\left\{\begin{array}{c}
A R M_{i}=(P-P E T)_{i}+A R M_{i-1} \\
N A C_{i}=C A D \times \ln \frac{\left(\mathrm{ARM}_{i}\right)}{C A D}
\end{array}\right. \\
& A L T_{i}=A R M_{i}-A R M_{i-1} \\
& E_{T R R_{i}}=\left\{\begin{array}{cl}
P+\left|A L T_{i}\right| & \text {, se } A L T<0 \\
E_{T T P} & \text {, se } A L T \geq 0
\end{array}\right.
\end{aligned}
$$


$D E F_{i}=E T P_{i}-E T R_{i}$

$E X C_{i}=\left\{\begin{array}{cl}0 & , \text { se } A R M_{i}<C A D \\ (P-P E T)_{i}-A L T_{i} & , \text { se } A R M_{i}=C A D\end{array}\right.$

em que CAD é a capacidade de água disponível $(\mathrm{mm})$; ARM é o armazenamento de água no solo $(\mathrm{mm})$; EXC é o excedente hidrico no sistema solo-plantaatmosfera $(\mathrm{mm}) ;$ DEF é a deficiência hídrica do sistema solo-planta-atmosfera $(\mathrm{mm})$; NAC é o valor de (P-ETo) negativo ; $\mathrm{P}$ é a precipitação $(\mathrm{mm})$; ETP é a evapotranspiração potencial $(\mathrm{mm})$; ETR é a evapotranspiração real $(\mathrm{mm})$; ALT é a alteração do armazenamento de água no solo do mês atual e do mês anterior $(\mathrm{mm})$ e, $i$ é o mês atual.

\section{ANÁLISE DOS DADOS}

Foi realizada a análise de correlação de Pearson para verificar a influência unitária dos elementos climáticos na produtividade de milho. A variável com maior nível de correlação foi realizada a análise multivariada de agrupamento por método hierárquico em função da maior variável correlacionada. As variáveis ficaram contidas em grupos podendo demostrar homogeneidade dentro de cada grupo e heterogeneidade entre as variáveis. Os grupos formados foram representados em gráfico conhecido como dendograma (SNEATH e SOKAL, 1973). A matriz de semelhança foi pela distância euclidiana e a ligação dos grupos com o método de Ward. A partir dos grupos formados foi realizado um histograma.

A modelagem foi realizada utilizando regressões lineares múltiplas (RLM) (Equação 17). As variáveis independentes foram as variáveis climáticas predominantes do período fenológico da cultura do milho safrinha: temperatura do ar $\left({ }^{\circ} \mathrm{C}\right)$, a precipitação pluviométrica $(\mathrm{mm})$, a evapotranspiração potencial $(\mathrm{mm})$, o déficit hídrico $(\mathrm{mm})$ e excedente hídrico $(\mathrm{mm})$. A variável dependente do modelo foi a produtividade do milho ( $\mathrm{kg} \mathrm{ha-1)}$.

Os modelos foram calibrados com dados do período de 2009 a 2014 de todas as 22 localidades, para ter uma ampla utilização no Estado de MS. Os testes dos modelos foram realizados independentes e de maneira separada para cada localidade, sendo com os dados de 2015 a 2018.

$Y=C L+a \times T m+b \times P+c \times E T P+d \times D E F+e \times E X C+\varepsilon$

em que, Y - a produtividade de milho dos municípios $\left(\mathrm{kg} \mathrm{ha}^{-1}\right) ; \mathrm{a}, \mathrm{b}, \mathrm{c}, \mathrm{d}, \mathrm{e}$; são os parâmetros do modelo (peso), Tm: temperatura média do ar $\left({ }^{\circ} \mathrm{C}\right), \mathrm{P}$ precipitação pluviométrica $(\mathrm{mm})$, ETP- evapotranspiração potencial $(\mathrm{mm}), \mathrm{DEF}$ déficit hídrico $(\mathrm{mm})$ e EXC- excedente hídrico $(\mathrm{mm})$, das fenologias selecionadas; CL - o coeficiente linear (termo constante) e $\varepsilon$ - o erro aleatório.

A fenologia da cultura do milho safrinha pode ser observada na Figura 2. Foi considerado na modelagem que o plantio do milho ocorre no início de abril e que a colheita ocorre em final de agosto. Os dados climáticos utilizados na modelagem de previsão foram T, P, ETP, DEF e EXC desse período. 


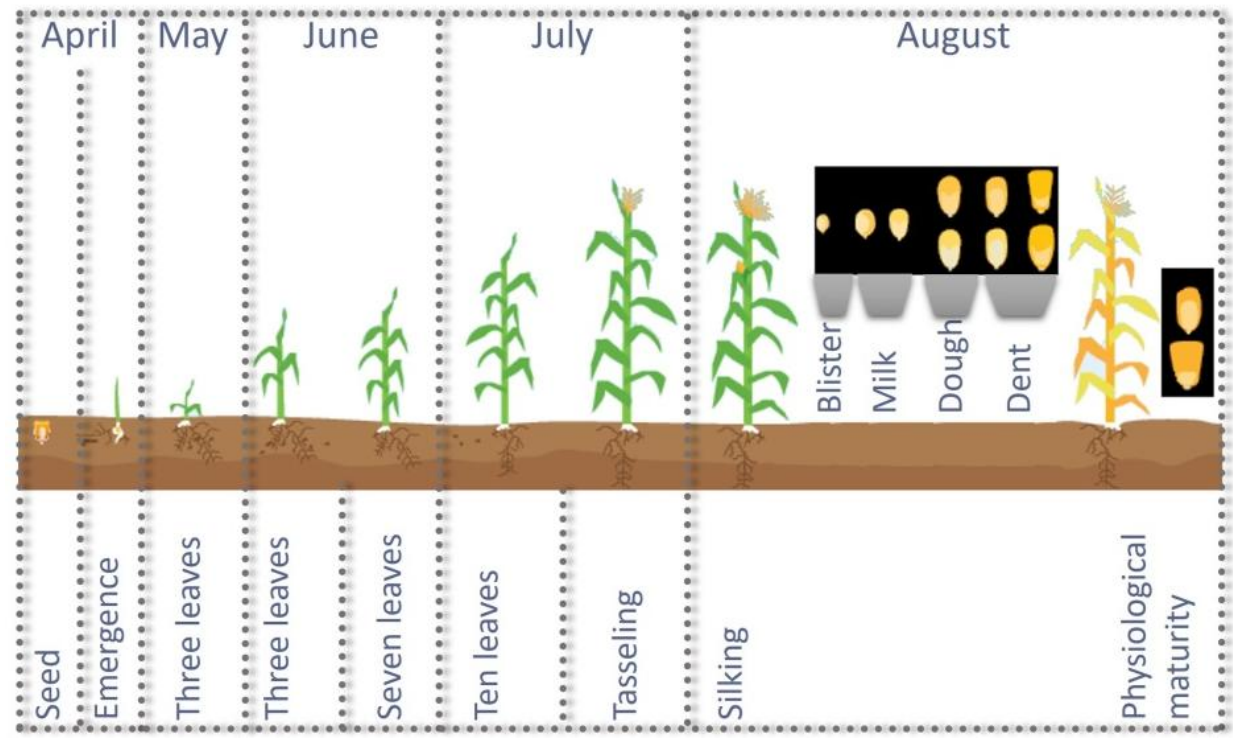

Figura 2 - Estágios fenológicos do milho na $2^{\circ}$ safra em MS. Fonte: Autor.

O método de estimativa empregado foi o mínimo quadrado ordinário (MQO), que busca minimizar a soma dos quadrados dos erros do modelo, por meio do sistema de optimização "generalized reduced gradiente" (GRG $)$. Para verificar a multicolinearidade das variáveis exploratórias utilizou a análise de correlação de Pearson ( $r$ ). Foram retiradas as variáveis exploratórias que demonstraram uma correlação de Pearson $r \geq|0,7|$. A normalidade foi verificada pelo teste de Kolmogorov-Smirnov (K-S).

A seleção do melhor modelo calibrado para cada região foi realizada utilizando os seguintes índices estatísticos: 1) correlação de Pearson ( $r)$; 2 ) Coeficiente de determinação ajustado (R2 adj); 3) Concordância de Wilmott (d); 4) Índice de Confiança (C) de Camargo e Sentelhas (1997); 5) Erro aleatório (Ea); 6) Erro sistemático (Es); 7) Erro absoluto máximo (EAmax); 8) erro quadrático médio (MSE); 9) Raiz quadrada do erro-médio (RMSE); 10) erro absoluto médio (MAE); 11) Média Percentual Absoluta do Erro (MAPE) (Equações 18 a 28). E para obter a maior confiabilidade nas regressões foram selecionadas apenas as regressões significativas pelo teste $\mathrm{F}$ a $5 \%$ de probabilidade.

$$
\begin{aligned}
& r=\frac{\sum_{i=1}^{n}\left(\text { PRODobs }_{i}-\overline{\text { PRODObs }}\right) \times\left(\text { PRODest }_{i}-\overline{\text { PRODest }^{2}}\right)}{\sqrt{\sum_{i=1}^{n}\left(\text { PRODobs }_{i}-\overline{\text { PRODObS }^{2}}\right.} \times \sqrt{\sum_{i=1}^{n}\left(\text { PRODest }_{i}-\overline{\text { PRODest }^{2}}\right)^{2}}} \\
& R^{2} a j=\left[1-\frac{\left(1-R^{2}\right) \times(n-1)}{N-k-1}\right] \\
& d=1-\frac{\sum_{i=1}^{N}\left(\text { PRODobs }_{i}-\text { PRODest }_{i}\right)^{2}}{\sum_{i=1}^{N}\left(\mid \text { PRODest }_{i}-\overline{\text { PROD }}|+| \text { PRODobs }_{i}-\bar{Y} \mid\right)} \\
& c=r . d
\end{aligned}
$$


$E a=\sqrt{\frac{\sum_{i=1}^{N}\left(\text { PROD }_{\text {est }}-\overline{\overline{P R O D})^{2}}\right.}{N}}$

$E S=\sqrt{\frac{\sum_{i=1}^{N}\left(P_{R O D_{o b s}}-\overline{P R O D}\right)^{2}}{N}}$

$M E=\max \left(\left|P R O D_{\text {obs }_{i}}-\operatorname{PROD}_{\text {est }_{i}}\right|\right)_{i=1}^{n}$

$M S E=\frac{\sum_{i=1}^{N}\left(\text { PROD }_{o b s_{i}}-\text { PROD }_{\text {est }}\right)^{2}}{N}$

$R M S E=\sqrt{\frac{\sum_{i=1}^{N}\left(\text { PROD }_{o b s_{i}}-\text { PROD }_{\text {est }}\right)_{i}}{N}}$

$M A E=\frac{\sum_{i=1}^{N}\left|P^{2} O D_{o b s_{i}}-P^{P O O D_{e s t}}\right|}{N}$

$\operatorname{MAPE}(\%)=\frac{\sum_{i=1}^{n}\left(\left|\frac{\text { PRODest }_{i}-\text { PRODobs }_{i}}{\text { PRODObs }_{i}}\right| \times 100\right)}{N}$

em que, PRODest $\mathrm{i}_{\mathrm{i}}$ Produtividade interpolada; PRODobs $\mathrm{s}_{\mathrm{i}}$ : Produtividade observada; $\mathrm{N}$ : número de dados e k: número de variáveis independentes na regressão.

O critério adotado para interpretar o desempenho foi pelo índice de confiança de Camargo e Sentelhas (1997) apresentado na Tabela 2.

Tabela 2 - Índice de confiança C estabelecido por Camargo e Sentelhas (1997)

\begin{tabular}{|c|c|}
\hline Valor de (C) & Desempenho \\
\hline$>0,85$ & Ótimo \\
\hline 0,76 a 0,85 & Muito Bom \\
\hline 0,66 a 0,75 & Bom \\
\hline 0,61 a 0,65 & Mediano \\
\hline 0,51 a 0,60 & Sofrível \\
\hline 0,41 a 0,50 & Mau \\
\hline$<0,40$ & Péssimo \\
\hline
\end{tabular}

\section{RESULTADOS E DISCUSSÃO}

A temperatura média do ar $(\mathrm{Tm})$ se mostrou mais elevada na região Norte do MS, principalmente nas localidades de Sonora e Coxim (Figura 3-A). As 
menores Tm registradas ocorreram nas localidades ao Sul como Amambai e Laguna Carapã. Em junho e julho ocorreram as menores Tm do estado. Em outubro e dezembro foram verificadas as maiores temperaturas do ar para região Norte e Sul, respectivamente.

A relação ETR/ETP (evapotranspiração real/evapotranspiração potencial) permite verificar o suprimento hídrico para a planta em relação a sua necessidade (CRUZ et al., 2011), ou seja, quanto mais próximo de " 1 " este índice se encontra, maior foi o suprimento hídrico pelo qual a planta foi submetida, consequentemente, menor a possibilidade de haver estresse hídrico e fechamento de estômato. É possível observar que nos meses de outubro a abril (Figura 3-C), época chuvosa e do período de safra do milho em Mato Grosso do Sul, a relação ETR/ETP esteve sempre acima de 0,8. No entanto, no período de cultivo do milho safrinha, principalmente em julho na qual a planta estará em pleno florescimento (Figura 2) e necessitará de muita água, a relação ETR/ETP se encontra abaixo de 0,5 em São Gabriel do Oeste, Chapadão do Sul, Coxim, Costa Rica e Sonora.

No estado do Mato Grosso do Sul, o período chuvoso vai de outubro a março, com as maiores precipitações se concentrando no período de janeiro a fevereiro (Figura 3-B). Consequentemente, os períodos de maior déficit hídrico (Figura 3-E) e menor armazenamento de água no solo (Figura 3- D) coincidem com o período de cultivo do milho safrinha, que vai de abril a agosto. A cultura do milho é muito sensível ao déficit hídrico nas fases fenológicas de florescimento e enchimento dos grãos, ocasionando perdas na produção de 20 a $50 \%$, dependendo do período e duração do estresse hídrico (PEGORARE et al., 2009).
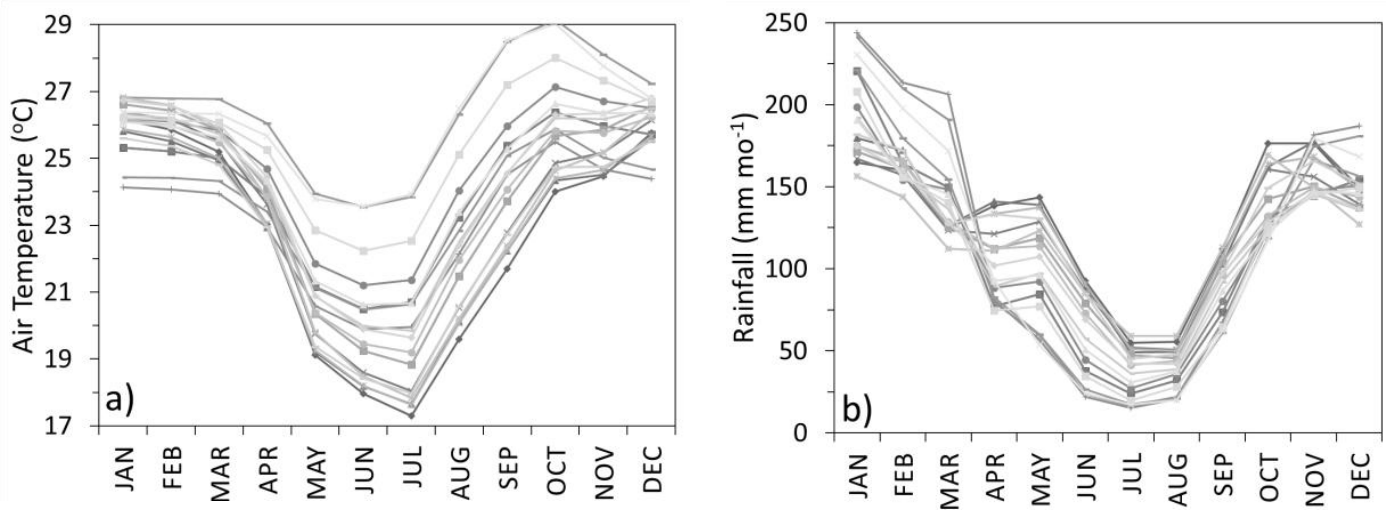

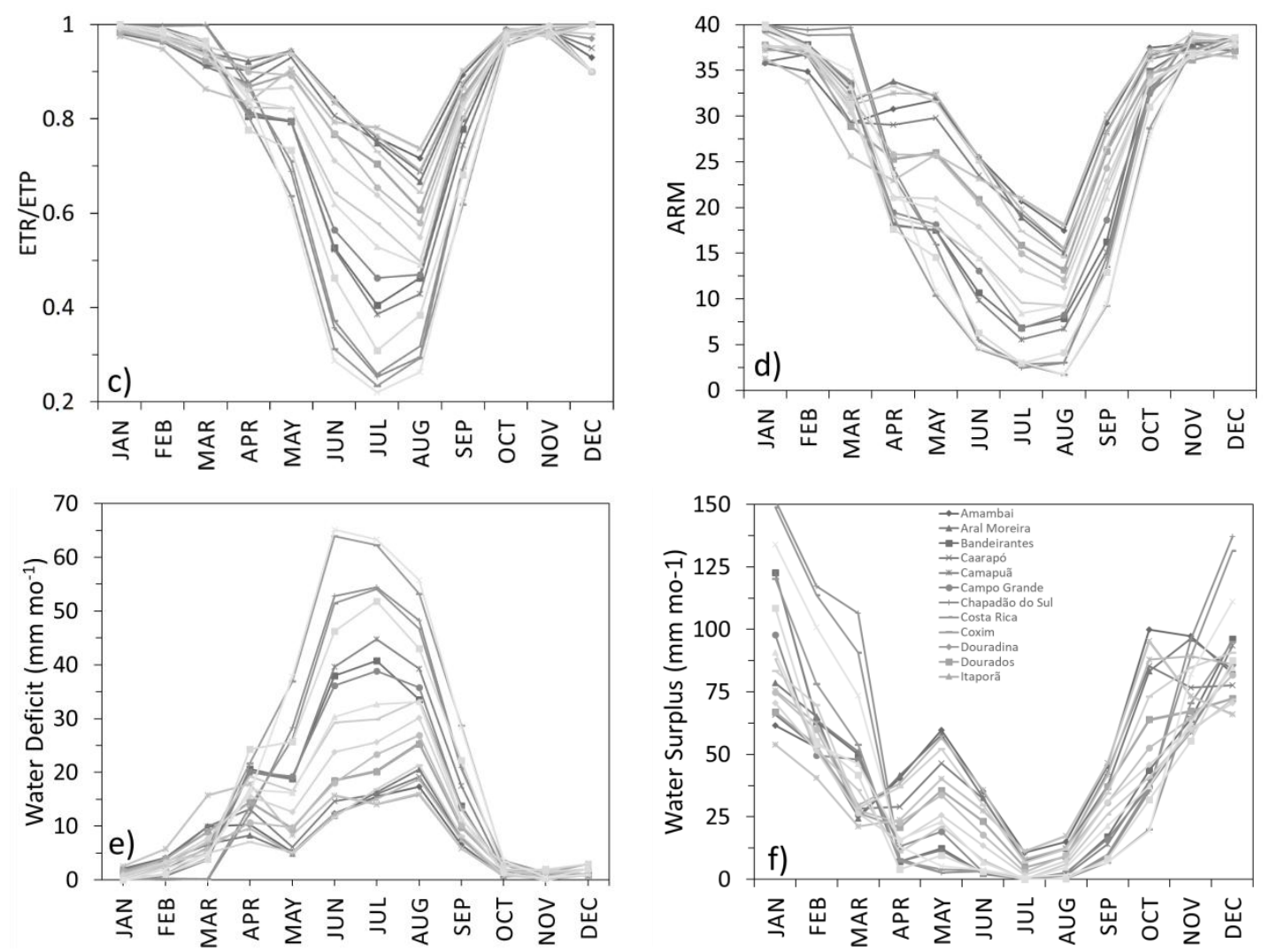

Figura 3 - Variação sazonal dos elementos climáticos para as localidades produtores de milho do Mato Grosso do Sul, Brasil.

Dentre as variáveis climáticas correlacionadas com a produtividade do milho, a temperatura do ar foi a que demonstrou correlação significativa com a produtividade (PROD), com um coeficiente de 0,33 (Tabela 3). Desta forma, foi realizada uma análise mais específica entre a relação $T$ x PROD, separando as localidades analisadas por cluster em função da temperatura do ar (Figura 4). É nítida a separação das localidades em dois grandes grupos de regiões. No grupo 1 encontram-se cidades localizadas no centro-sul do estado, como Naviraí, Dourados e Ponta Porã, com média de temperatura do ar de $23^{\circ} \mathrm{C}$. Já no grupo II, estão as cidades do centro-norte de Mato Grosso do Sul na qual a temperatura do ar média anual encontrou-se em $25^{\circ} \mathrm{C}$, como Sidrolândia, Camapuã e Bandeirantes.

Tabela 3 - Correlação de Pearson entre as variáveis climáticas e a produtividade de milho no Mato Grosso do Sul.

\begin{tabular}{lllllll}
\hline & $P R O D$ & $T$ & $P$ & $E T P$ & $D E F$ & $E X C$ \\
\hline PROD & 1,000 & & & & & \\
T & $0,33^{*}$ & 1,00 & & & & \\
P & $-0,24$ & $-0,74$ & 1,00 & & & \\
ETP & 0,09 & 0,80 & $-0,62$ & 1,00 & & \\
DEF & $-0,12$ & 0,78 & $-0,84$ & 0,79 & 1,00 & \\
EXC & $-0,28$ & $-0,68$ & 0,92 & $-0,54$ & $-0,61$ & 1,00 \\
\hline
\end{tabular}


*Significativo ao nível de $95 \%$ de confiança pelo test-F

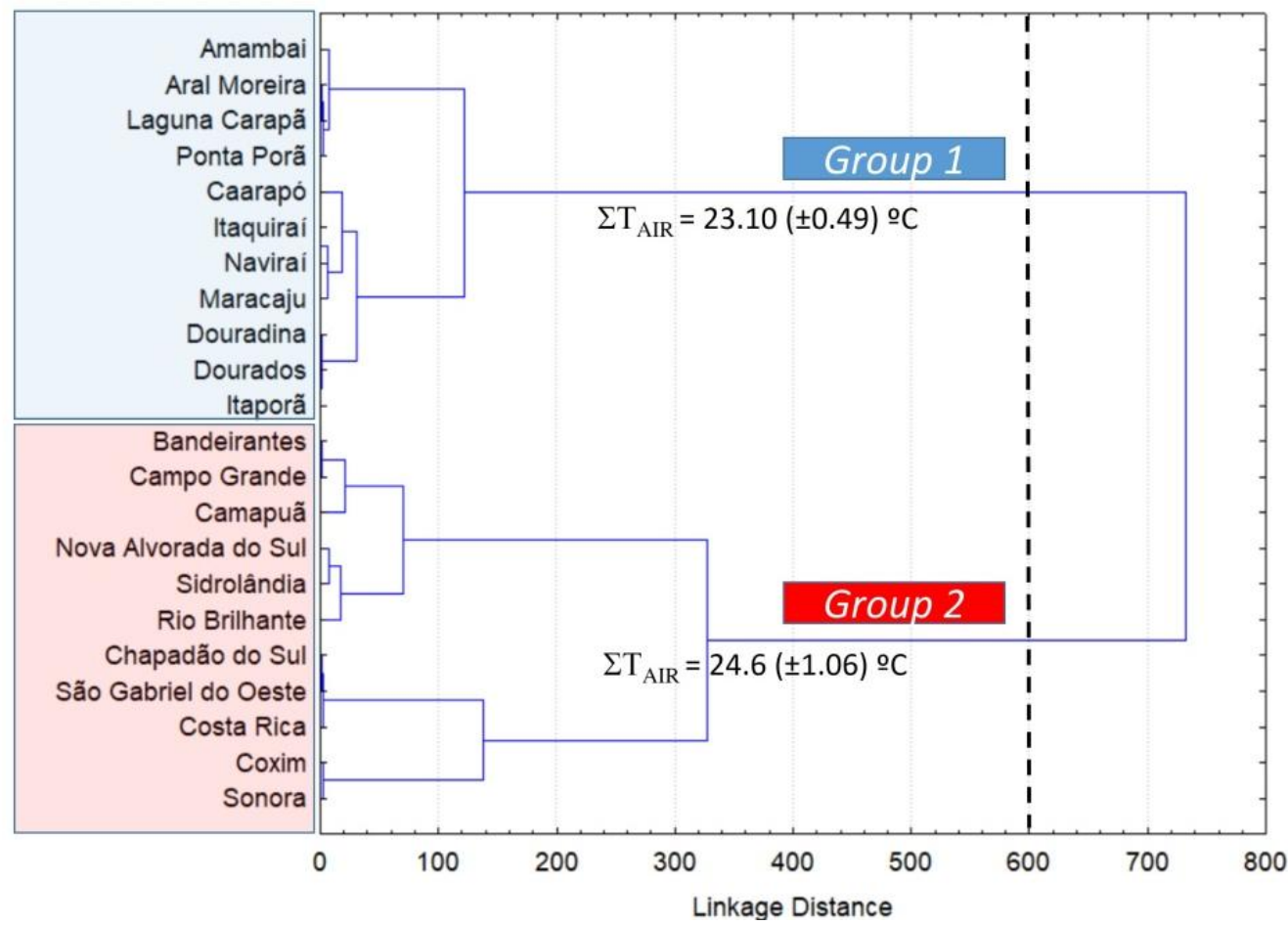

Figura 4 - Dendrograma de identificação dos grupos (GI e GII) usando a temperatura média do ar do Mato Grosso do Sul.

A produtividade média das localidades da região norte (Grupo 2) foi maior em relação as localidades do sul do estado (Grupo 1) (Figura 5). A diferença foi de $1,5^{\circ} \mathrm{C}$ na temperatura média entre os dois grupos (Figura 4), enquanto da produtividade foi de $231,2 \mathrm{~kg} \mathrm{ha}^{-1}$. Essa diferença de produtividade está associada a diversos fatores climáticos e não climáticos. Dentre os fatores climáticos, a temperatura do ar é o que mais influencia na produtividade do milho nas localidades analisadas em Mato Grosso do Sul (Tabela 3).

O milho é uma planta cuja fixação fotossintética do carbono é pela via C4. Plantas com este tipo de mecanismo de concentração do CO2 são mais adaptadas a ambientes com temperaturas mais elevadas (TAIZ e ZEIGER, 2009). A temperatura ideal para o desenvolvimento do milho, da emergência à floração, está compreendida entre 24 e $30^{\circ} \mathrm{C}$, em que as temperaturas do ar noturnas elevadas por longos períodos podem causar diminuição do rendimento de grãos e provocar senescência precoce das folhas (ALVARENGA et al., 2010).

A duração dos estados fenológicos do milho está diretamente relacionada à temperatura do ar do local de desenvolvimento da planta e da soma calórica requerido pelo material genético utilizado (GADIOLI et al., 2000). Dessa forma, visto a importância da $T$ na determinação da produtividade no milho, foi necessário observar a necessidade calórica nas fases vegetativas e reprodutivas do híbrido a ser utilizado para cada região. 


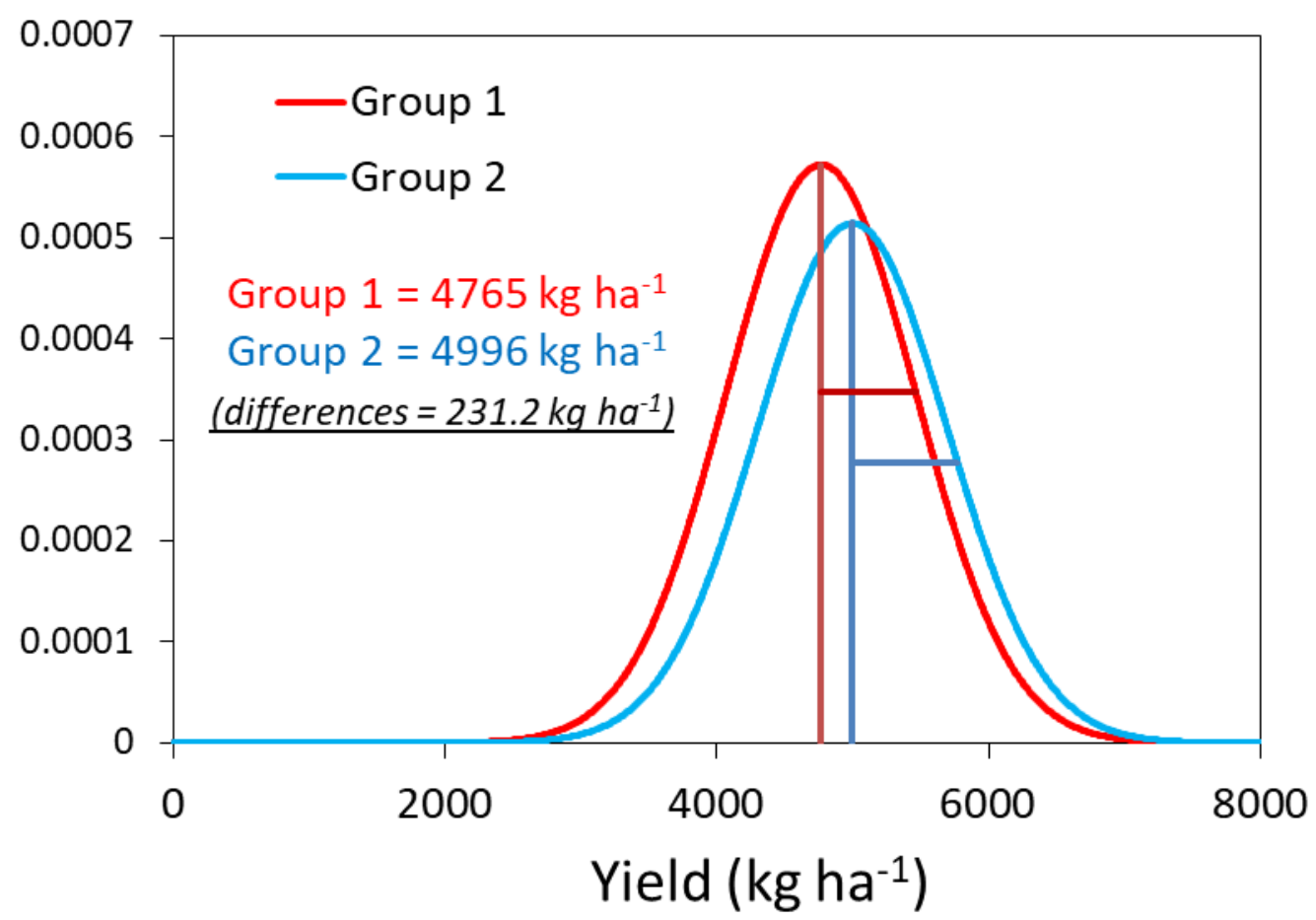

Figura 5 - Distribuição da produtividade de milho safrinha no Mato Grosso do Sul em função dos grupos climáticos.

O modelo regional ajustado para MS em função dos dados climáticos foi estatisticamente significativo a $1 \%$ (teste $F$ ), o que indica que o conjunto de variáveis climáticas utilizadas tem forte influência estatística sobre a produtividade do milho safrinha no MS (Tabela 4).

Tabela 4 - Análise de variância da regressão Linear Múltipla utilizando como variável dependente a produtividade de milho na safrinha e como variáveis independentes os elementos climáticos do ciclo da cultura. $\mathrm{GL}=$ grau de liberdade, $\mathrm{SQ}=$ soma dos quadrados e QM = quadrado médio

\begin{tabular}{llllll}
\hline & & & & & $F$ \\
sl & SQ & MQ & $F$ & de \\
\hline Regressão & 15 & 49093497,02 & 3272899,80 & 16,25 & $5.93039 \mathrm{E}^{-22}$ \\
Resíduo & 116 & 23352683,09 & 201316,23 & & \\
Total & 131 & 72446180,11 & & & \\
\hline
\end{tabular}

O modelo calibrado com os elementos climáticos para estimar a produtividade de milho na safrinha foi acurado, uma vez que demonstrou um erro médio de $7 \%$ (MAPE) (Tabela 5 ). Vale ressaltar que um MAPE (erro) de apenas $7 \%$ neste modelo é considerado muito baixo, pois em um município com produtividade média de $5.000 \mathrm{~kg} \mathrm{ha}^{-1}$ ocorre uma variação média de apenas \pm $350 \mathrm{~kg} \mathrm{ha}^{-1}$. O coeficiente de determinação ajustado (R2aj) foi de 0,67, o que indica um ótimo ajuste do modelo, ou seja, $67 \%$ das variações nas 
produtividades de milho são explicadas pelas variáveis climáticas do ciclo da cultura (Tabela 4).

Tabela 5 - Desempenho da calibração do modelo de previsão como variável dependente a produtividade de milho safrinha e como variáveis independentes os elementos climáticos do ciclo da cultura.

\begin{tabular}{ll}
\hline ÍNDICES & VALORES \\
\hline $\mathrm{r}$ & 0,82 \\
$\mathrm{R}^{2}$ & 0,67 \\
$\mathrm{~d}$ & 0,89 \\
$\mathrm{C}$ & 0,73 \\
$\mathrm{Ea}$ & 346,24 \\
$\mathrm{ES}$ & 238,80 \\
EAmax & 1223,50 \\
MSE & 176914,3 \\
RMSE & 420,61 \\
MAE & 330,32 \\
MAPE & 6,91 \\
\hline
\end{tabular}

As variáveis climáticas do ciclo que demonstraram os maiores níveis de correlações na estimativa da produtividade de milho safrinha no MS foram a temperatura do ar de abril (Tabr, $r=-375,41)$ e a Tmaio $(r=215,14)$. Por sua vez, as variáveis que evidenciaram as menores correlações foram a ETPabr e Pabr (Tabela 6).

A análise de elasticidade da Tabr demonstra que a produtividade do milho safrinha no MS tem elevada elasticidade, com -375,41 e alta significância $(p=0,00001)$. Esta elasticidade indica que uma variação de $1^{\circ} \mathrm{C}$ no Tabr pode ocasionar uma redução de $375,41 \mathrm{~kg}$ ha-1 na produtividade (Tabela 7 ). Ao total dos primeiros três meses do período da safrinha (abril, maio e junho), observou-se uma elasticidade de 774,34, o que indica que a variação de $1^{\circ} \mathrm{C}$ na $\mathrm{T}$ pode ocasionar uma variação de até $774 \mathrm{~kg}$ ha-1 na produtividade, o que corresponde a aproximadamente 13 sacas.

Tabela 7 - Coeficientes estimados no modelo regional de previsão da produtividade de milho na safrinha do MS em função dos elementos climáticos do ciclo da cultura.

\begin{tabular}{lllll}
\hline & Coeficientes & $\begin{array}{l}\text { Erro } \\
\text { padrão }\end{array}$ & teste t & valor-P \\
\hline Interseção & 12385,41 & 1737,90 & 7,13 & 0,001 \\
Tabr & $-375,41$ & 75,75 & $-4,96$ & 0,00001 \\
Tmai & 215,15 & 67,16 & 3,20 & 0,002 \\
Tjun & 183,78 & 63,32 & 2,90 & 0,004 \\
Pabr & 7,34 & 5,45 & 1,35 & 0,181 \\
Pmai & 14,71 & 7,15 & 2,06 & 0,042 \\
Pjun & 15,89 & 5,34 & 2,98 & 0,004 \\
ETPabr & $-3,40$ & 24,05 & $-0,14$ & 0,888 \\
ETPmai & $-141,54$ & 25,32 & $-5,59$ & 0,001 \\
ETPjun & 47,23 & 22,85 & 2,07 & 0,041
\end{tabular}




\begin{tabular}{lllll} 
DEFabr & 12,52 & 6,05 & 2,07 & 0,041 \\
DEFmai & 14,27 & 8,11 & 1,76 & 0,081 \\
DEFjun & 15,25 & 7,11 & 2,14 & 0,034 \\
EXCabr & $-16,80$ & 5,62 & $-2,99$ & 0,003 \\
EXCmai & $-16,89$ & 7,61 & $-2,22$ & 0,028 \\
EXCjun & $-16,88$ & 6,28 & $-2,69$ & 0,008 \\
\hline
\end{tabular}

O modelo testado com dados aleatórios de cada localidade observou-se uma elevada acurácia e precisão do modelo regional, o MAPE variou de 3 a $11 \%$ e R2 variou de 0,52 a 0,80 (Tabela 8 ).

Tabela 8 - Índices estatísticos da validação (teste) do modelo regional para os municípios produtores de Milho safrinha do Mato Grosso do Sul.

\begin{tabular}{|c|c|c|c|c|c|c|c|c|c|c|c|}
\hline Município & $\mathrm{R}$ & $\mathrm{R}^{2}$ & D & C & $\mathrm{Ea}$ & Es & EAmax & MSE & RMSE & MAE & MAPE \\
\hline Amambai & 0,93 & 0,86 & 0,89 & 0,82 & 197,14 & 377,50 & 622,24 & 181366,94 & 425,87 & 360,36 & 6,94 \\
\hline Aral Moreira & 0,82 & 0,67 & 0,90 & 0,74 & 395,65 & 88,82 & 665,11 & 164426,12 & 405,49 & 346,41 & 7,41 \\
\hline Bandeirantes & 0,93 & 0,87 & 0,94 & 0,88 & 196,30 & 232,38 & 495,01 & 92536,54 & 304,20 & 235,20 & 4,77 \\
\hline Caarapó & 0,85 & 0,73 & 0,92 & 0,78 & 336,45 & 189,15 & 560,24 & 148974,72 & 385,97 & 328,73 & 6,41 \\
\hline Camapuã & 0,93 & 0,87 & 0,85 & 0,79 & 194,83 & 514,29 & 976,12 & 302451,13 & 549,96 & 413,23 & 10,71 \\
\hline Campo Grande & 0,92 & 0,84 & 0,94 & 0,86 & 215,21 & 134,90 & 522,08 & 64515,16 & 254,00 & 184,02 & 3,70 \\
\hline Chapadão do Sul & 0,90 & 0,81 & 0,78 & 0,70 & 167,15 & 568,94 & 1223,50 & 351633,07 & 592,99 & 453,40 & 7,95 \\
\hline Costa Rica & 0,87 & 0,76 & 0,82 & 0,71 & 222,02 & 538,98 & 1023,60 & 339790,81 & 582,92 & 516,87 & 8,99 \\
\hline Coxim & 0,92 & 0,85 & 0,88 & 0,81 & 180,42 & 399,95 & 1007,99 & 192508,39 & 438,76 & 289,13 & 7,68 \\
\hline Douradina & 0,92 & 0,85 & 0,91 & 0,84 & 241,37 & 351,88 & 712,18 & 182080,00 & 426,71 & 386,17 & 7,54 \\
\hline Dourados & 0,99 & 0,99 & 0,93 & 0,92 & 73,83 & 399,45 & 552,67 & 165008,69 & 406,21 & 387,31 & 7,48 \\
\hline Itaporã & 0,93 & 0,86 & 0,94 & 0,87 & 230,39 & 274,40 & 495,21 & 128374,76 & 358,29 & 348,88 & 7,83 \\
\hline Itaquiraí & 0,95 & 0,91 & 0,77 & 0,74 & & & 726,21 & 228734,27 & 478,26 & 427,67 & 9,45 \\
\hline Laguna Carapã & 0,93 & 0,87 & 0,93 & 0,87 & 205,08 & 193,46 & 560,55 & 79486,13 & 281,93 & 191,57 & 4,08 \\
\hline Maracaju & 0,98 & 0,95 & 0,98 & 0,96 & 130,18 & 117,41 & 339,52 & 30732,91 & 175,31 & 135,14 & 2,99 \\
\hline Naviraí & 0,72 & 0,52 & 0,83 & 0,60 & 473,31 & 113,82 & 867,40 & 236974,40 & 486,80 & 398,15 & 8,31 \\
\hline $\begin{array}{l}\text { Nova Alvorada do } \\
\text { Sul }\end{array}$ & 0,88 & 0,78 & 0,92 & 0,81 & 281,39 & 278,92 & 677,73 & 156977,51 & 396,20 & 345,04 & 7,46 \\
\hline Ponta Porã & 0,87 & 0,76 & 0,88 & 0,76 & 311,09 & 305,57 & 868,35 & 190151,68 & 436,06 & 346,85 & 7,45 \\
\hline Rio Brilhante & 0,74 & 0,55 & 0,84 & 0,63 & 415,05 & 150,36 & 987,90 & 194873,65 & 441,44 & 323,41 & 7,58 \\
\hline $\begin{array}{l}\text { São Gabriel do } \\
\text { Oeste }\end{array}$ & 0,89 & 0,79 & 0,89 & 0,80 & 255,88 & 328,31 & 954,03 & 173266,85 & 416,25 & 282,03 & 4,93 \\
\hline Sidrolândia & 0,92 & 0,85 & 0,94 & 0,87 & 197,04 & 76,87 & 317,38 & 44734,51 & 211,51 & 191,72 & 3,86 \\
\hline Sonora & 0,85 & 0,72 & 0,77 & 0,65 & 196,16 & 451,71 & 863,52 & 242515,63 & 492,46 & 375,83 & 8,52 \\
\hline AVERAGE & 0,89 & 0,80 & 0,88 & 0,79 & 242,01 & 296,25 & 728,11 & 176914,27 & 406,71 & 330,32 & 6,91 \\
\hline MAX & 0,99 & 0,99 & 0,98 & 0,96 & 473,31 & 568,94 & 1223,50 & 351633,07 & 592,99 & 516,87 & 10,71 \\
\hline MIN & 0,72 & 0,52 & 0,77 & 0,60 & 73,83 & 76,87 & 317,38 & 30732,91 & 175,31 & 135,14 & 2,99 \\
\hline
\end{tabular}

Foi realizada a comparação da produtividade prevista com a produtividade real do milho durante seis safrinhas para os municípios analisados, notou que o modelo de previsão ficou próximo da realidade na maioria das localidades (Figura 6). Para Maracaju, Campo Grande e Sidrolândia, 
a produtividade estimada foi próxima da produtividade real, com um erro médio inferior a 4\% (MAPE), o que demonstrou alta confiabilidade no modelo (Tabela 8). Camapuã, Itaquiraí e Costa Rica obteve a maior diferença entre a produtividade real e estimada, com erros de 10,$71 ; 9,45$ e $9 \%$, respectivamente.

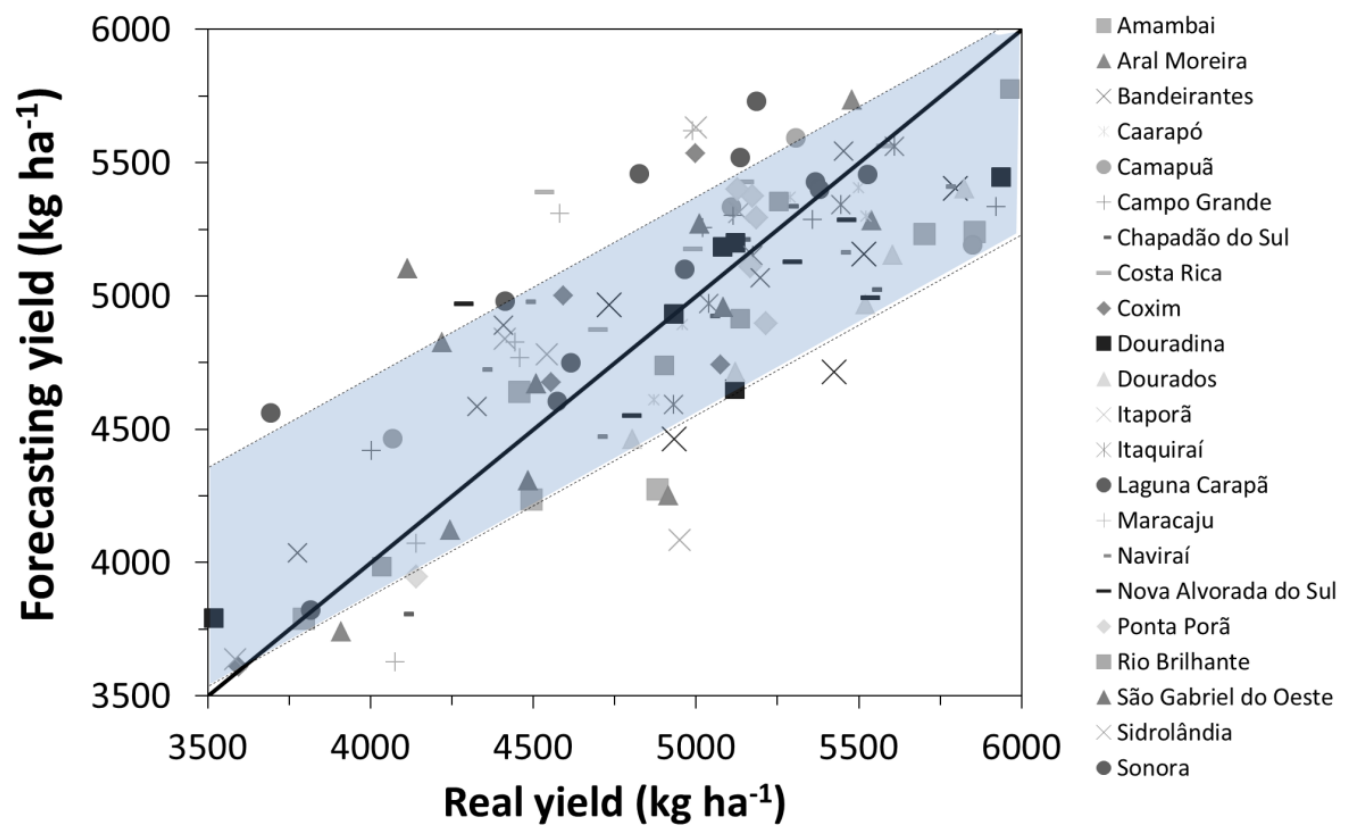

Figura 6 - Desempenho do teste do modelo regional de previsão de produtividade do milho safrinha para as localidades do Mato Grosso do Sul. Legenda: linha cinza é linha $1: 1$; linhas tracejadas é o intervalo de confiança a 95\%.

A variação espacial da produtividade real e prevista do milho safrinha em Mato Grosso do Sul pode ser observada na Figura 7. Na região sul, a produtividade real do milho variou de 4500 a $5000 \mathrm{~kg} \mathrm{ha}^{-1}$, enquanto que na região central demonstrou produtividades superiores a 5500 sacas ha- ${ }^{-1}$, como observado em Ivinhema, Anaurilândia e Batayporã (Figura 7B). Os modelos regressivos com elevada acurácia conseguiram prever a variação espacial da produtividade de milho safrinha em Mato Grosso do Sul (Figura 7B).

O desvio entre a produtividade real e estimada de milho safrinha em Mato Grosso do Sul pode ser observado na Figura 8 . Notou-se que em $86 \%$ do território do Mato Grosso do Sul, os modelos em função das condições climáticas demonstraram desvios menores que $150 \mathrm{~kg} \mathrm{ha}^{-1}$. Em algumas localidades como Costa Rica, Alcinópolis, Camapuã, Maracaju, e Eldorado, os modelos demonstraram desvios entre 150 e $300 \mathrm{~kg} \mathrm{ha}^{-1}$, entretanto, essas localidades representam menos de $10 \%$ da área do Mato Grosso do Sul (Figura 9). 

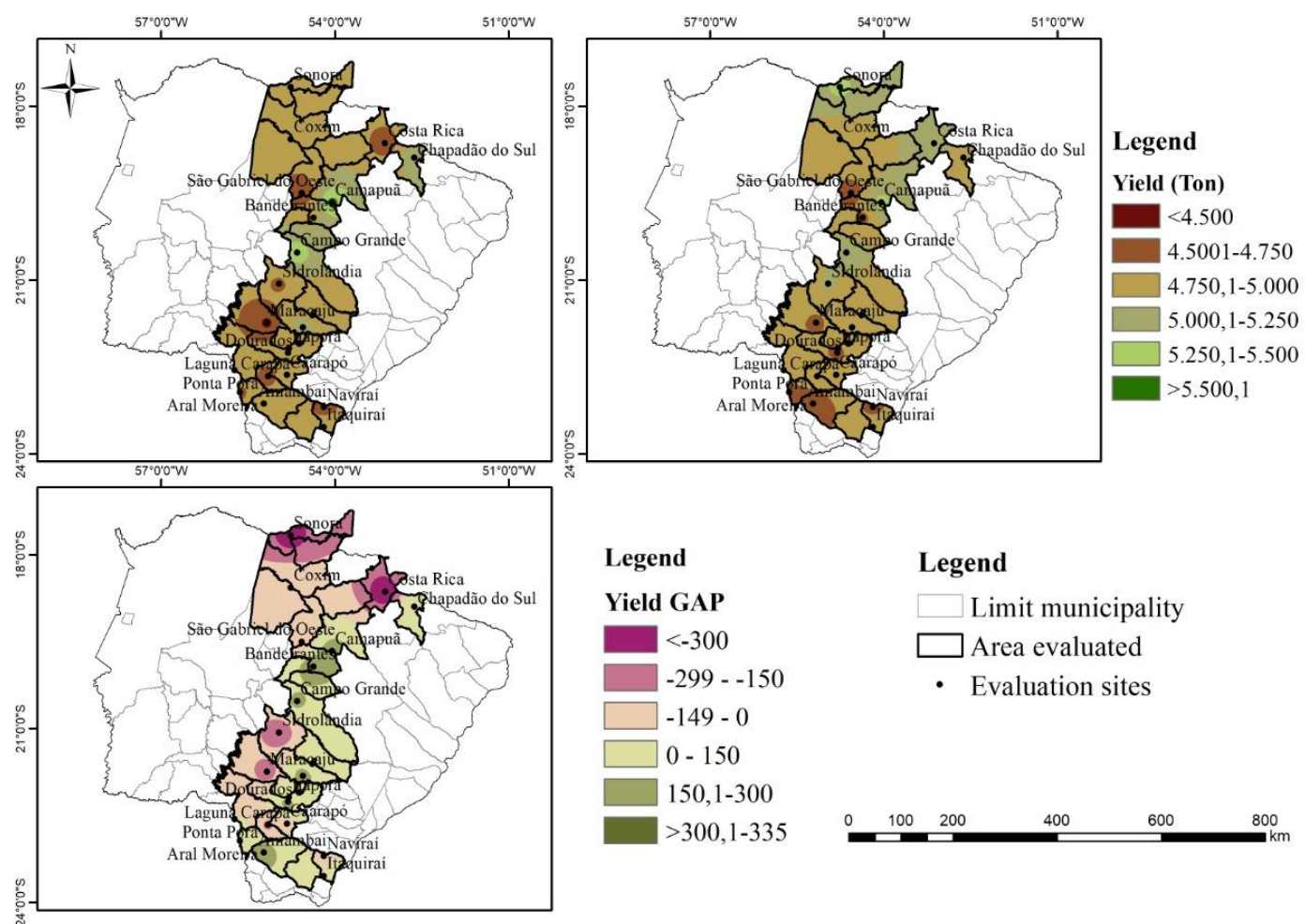

Figura 9 - Mapeamento da produtividade real (a) prevista (b) e desvio entre as produtividades reais e previstas (c) do milho pelo modelo regional em função das condições climáticas do Mato Grosso do Sul.

\section{CONCLUSÃO}

O modelo desenvolvido para estimar a produtividade do milho safrinha em função das variáveis climáticas foi significativo $(p<0,05)$, com alta precisão (R2aj: 0,80) e acurácia (MAPE: 6,91\%).

O modelo calibrado apresentou relação significativa $(p<0,05)$ entre a produtividade do milho safrinha e a temperatura do ar no período de abril e maio, portanto, essa variável meteorológica pode ser utilizada como indicador de riscos climáticos em sistemas de produção de milho no Estado do Mato Grosso do Sul.

\section{REFERÊNCIAS}

ALLEN, R. G.; SMITH, M.; PERRIER, A.; PEREIRA, L. S. An update for the definition of reference evapotranspiration. ICID bulletin, v. 43, n. 2, p. 1-34, 1994.

ALLEN, R. G.; PEREIRA, L. S.; RAES, D.; SMITH, M. Crop evapotranspirationGuidelines for computing crop water requirements-FAO Irrigation and drainage paper 56. Fao, Rome, v. 300, n. 9, p. D05109, 1998. 
AlVARENGA, R. C.; NOVOTNY, E. H.; PEREIRA-FILHO, I. A.; SANTANA, D. P.; PEREIRA, F. T. F.; HERNANI, L. C. Cultivo do milho. Sete Lagoas: Embrapa Milho e Sorgo, 2010.

APARECIDO, L. E. D. O.; ROLIM, G. D. S.; MORAES, J. R. D. S. C.; ROCHA, H. G.; LENSE, G. H. E.; SOUZA, P. S. Agroclimatic zoning for urucum crops in the state of Minas Gerais, Brazil. Bragantia, v. 77, n. 1, p. 193-200, 2018.

ARAUS, José Luis; SERRET, María Dolors; EDMEADES, Greg. Phenotyping maize for adaptation to drought. Frontiers in physiology, v. 3, p. 305, 2012.

BASSO, B.; CAMMARANO, D.; CARFAGNA, E. Review of crop yield forecasting methods and early warning systems. In: Proceedings of the first meeting of the scientific advisory committee of the global strategy to improve agricultural and rural statistics, FAO Headquarters, Rome, Italy. p. 18-19, 2013.

BERGAMASCHI, H.; DALMAGO, G. A.; BERGONCI, J. I.; BIANCHI, C. A. M.; MÜLLER, A. G.; COMIRAN, F.; HECKLER, B. M. M. Distribuição hídrica no período crítico do milho e produção de grãos. Pesquisa Agropecuária Brasileira, v. 39, n. 9, p. 831-839, 2004.

CAMARGO, A. P.; SENTELHAS, P. C. Avaliação do desempenho de diferentes métodos de estimativa da evapotranspiração potencial no Estado de São Paulo, Brasil. Revista Brasileira de agrometeorologia, v. 5, n. 1, p. 89-97, 1997.

CEGLAR, A.; TORETI, A. ; PRODHOMME, C.; ZAMPIERI, M. ; TURCO, M.; DOBLASREYES, F. J. Land-surface initialisation improves seasonal climate prediction skill for maize yield forecast. Scientific reports, v. 8, n. 1, p. 1322, 2018.

CONAB - Companhia Nacional de Abastecimento. Acomp. safra bras. grãos, v. 7 Safra 2017/18 - Sétimo levantamento, Brasília, p. 1-139 abril 2018.

CRUZ, P. G.; SANTOS, P. M.; PEZZOPANE, J. R. M.; OliveiRA, P. P. A.; ARAUJO, L. C. Modelos empíricos para estimar o acúmulo de matéria seca de capim - marandu com variáveis agrometeorológicas. Pesquisa Agropecuária Brasileira, v. 46, n. 7, p. 675-681, 2011.

GADIOLI, J. L.; DOURADO-NETO, D.; GARCÍA, A. G.; BASANTA, M. D. V. Temperatura do ar, rendimento de grãos de milho e caracterização fenológica associada à soma calórica. Scientia Agricola, v. 57, n. 3, p. 377-383, 2000.

GARCIA, R. A.; CECCON, G.; SUTIER, G. A. D. S.; SANTOS, A. L. F. D. Soybeancorn succession according to seeding date. Pesquisa Agropecuária Brasileira, v. 53, n. 1, p. 22-29, 2018.

GONG, F.; WU, X.; ZHANG, H.; CHEN, Y.; WANG, W. Making better maize plants for sustainable grain production in a changing climate. Frontiers in plant science, v. 6, p. $835,2015$.

HATFIELD, J. L.; PRUEGER, J. H. Temperature extremes: Effect on plant growth and development. Weather and climate extremes, v. 10, p. 4-10, 2015.

JAYAKUMAR, M.; RAJAVEL, M. Coffee yield forecasting using climate indices based agrometeorological model in Kerala. Mausam, v. 68, p. 309-316, 2017. HATFIELD, J. L. et al. AND D. Wolfe.; Climate Impacts on Agriculture: Implications for Crop Production. Agronomy Journal • Volume 103, Issue 2. 2011 
KRIGE, D. G. A statistical approach to some basic mine valuation problems on the Witwatersrand. Journal of the Southern African Institute of Mining and Metallurgy, v. 52, n. 6, p. 119-139, 1951.

MONTEIRO, J. E. B. A.; ASSAD, E. D.; SENTELHAS, P. C., AZEVEDO, L. C. Modeling of corn yield in Brazil as a function of meteorological conditions and technological level. Pesquisa Agropecuária Brasileira, v. 52, n. 3, p. 137-148, 2017.

OGUTU, G. E.; FRANSSEN, W. H.; SUPIT, I.; OMONDI, P.; HUTJES, R. W. Probabilistic maize yield prediction over East Africa using dynamic ensemble seasonal climate forecasts. Agricultural and forest meteorology, v. 250, p. 243261, 2018.

OLIVEIRA, L. A.; MIRANDA, J. H.; COOKE, R. A. Water management for sugarcane and corn under future climate scenarios in Brazil. Agricultural water management, v. 201, p. 199-206, 2018.

PEgORARE, A. B.; FEDATTO, E.; PEREIRA, S. B.; SOUZA, L. C.; FIETZ, C. R. Irrigação suplementar no ciclo do milho" safrinha" sob plantio direto. Embrapa Agropecuária Oeste-Artigo em periódico indexado (ALICE), 2009.

PENG, J.; KIM, M.; KIM, Y.; JO, M.; KIM, B.; SUNG, K.; LV, S. Constructing Italian ryegrass yield prediction model based on climatic data by locations in South Korea. Grassland science, v. 63, n. 3, p. 184-195, 2017.

RAY, D.K.; GERBER, J.S.; MACDONALD, G.K.; WEST, P.C. Climate variation explains a third of global crop yield variability. Nature communications, v. 6, p. 5989, 2015.

RODRIGUEZ, D.; VOIL, P.; HUDSON, D.; BROWN, J. N.; HAYMAN, P.; MARROU, $\mathrm{H}$.; MEINKE, $\mathrm{H}$. Predicting optimum crop designs using crop models and seasonal climate forecasts. Scientific reports, v. 8, n. 1, p. 2231, 2018.

SCHAUBERGER, B., ARCHONTOULIS, S., ARNETH, A., BALKOVIC, J., CIAIS, P., DERYNG, D.; ELLIOTT, J.; FOLBERTH, C.; KHABAROV, N.; MÜLLER, C.; PUGH, T. A.; ROLINSKI, S.; SCHAPHOFF, S.; SCHMID, E.; WANG, X.; SCHLENKER, W; FRIELER, K. Consistent negative response of US crops to high temperatures in observations and crop models. Nature Communications, v. 8, p. 13931, 2017.

SNEATH, P. H. A.; SOKAL, R. R. Numerical taxonomy. San Francisco: Freeman and

Co., 1973. 573 p.

TAIZ, L.; ZEIGER, E. Auxina: o hormônio de crescimento. Fisiologia vegetal, v. 3, p. 449-484, 2009.

THORNTHWAITE, C. W.; MATHER, J. R. The water balance. Centerton: Drexel Institute of Technology, Laboratory of Climatology, 1955. 104p. Publications in climatology, v. 8, n. 1, 1955.

WALTHALL, C. L.; HATFIELD, J.; BACKLUND, P.; LENGNICK, L.; MARSHALL, E.; WALSH, M.; ADKINS, S.; AILLERY, M.; AINSWORTH, E. A.; AMMANN, C.; ANDERSON, C. J.; BARTOMEUS, I.; BAUMGARD, L. H.; BOOKER, F.; BRADLEY; B.; BLUMENTHAL, D. M.; BUNCE, J.; BURKEY, K.; DABNEY, S. M.; DELGADO, J. A.; DUKES, J.; FUNK, A.; GARRETT, K.; GLENN, M.; GRANTZ, D. A.; GOODRICH, D.; HU, S.; IZAURRALDE, R. C.; JONES, R. A. C.; KIM, S-H.; LEAKY, A. D. B.; 
LEWERS, K.; MADER, T. L.; MCCLUNG, A.; MORGAN, J.; MUTH, D. J.; NEARING, M.; OOSTERHUIS, D. M.; ORT, D.; PARMESAN, C.; PETTIGREW, W. T.; POLLEY, W.; RADER, R.; RICE, C.; RIVINGTON; M.; ROSSKOPF, E.; SALAS, W. A.; SOLLENBERGER, L. E.; SRYGLEY, R; STÖCKLE, C.; TAKLE, E. S.; TIMLIN, D.; WHITE, J. W.; WINFREE, R.; WRIGHT-MORTON, L.; ZISKA, L. H. Climate change and agriculture in the United States: effects and adaptation. USDA technical bulletin 1935, Washington, DC, p 186, 2012 .. 